\title{
Prospective epidemiological update on traumatic spinal cord injury in Ireland
}

\author{
Éimear Smith ${ }^{1,2} \cdot$ Patricia Fitzpatrick $^{3} \cdot$ Frank Lyons $^{4} \cdot$ Seamus Morris $^{2,1} \cdot$ Keith Synnott $^{2,1}$
}

Received: 20 November 2018 / Revised: 2 January 2019 / Accepted: 7 January 2019

(c) International Spinal Cord Society 2019

\begin{abstract}
Study design Prospective population-based epidemiological study on traumatic spinal cord injury in Ireland Objectives To provide updated data for the global TSCI repository

Setting Republic of Ireland

Methods All cases of TSCI acquired during 2016 were included. ISCoS core dataset was collected on all cases. Descriptive statistics are reported.

Results Overall crude incidence of TSCI was 12.8 per million (61 cases). Males accounted for $75.4 \%$. Mean age at onset was 52.8 (19.9) years. Falls was the most common aetiology, 60.7\% and AIS D was the most common injury level/AIS classification, $32.8 \%$. The majority of patients $(59 \%)$ were discharged home.

Conclusions Overall incidence of TSCI has changed very little since 2000 but many aspects of injury such as age and aetiologies are different. This data can now be included in the next TSCI global mapping update.
\end{abstract}

Sponsorship Health Research Board, Ireland.

\section{Introduction}

Current information on the epidemiology of traumatic and non-traumatic spinal cord injury (TSCI/NTSCI) is sought by the global mapping projects $[1,2]$. The only contribution from Ireland to this repository dates back to 2000 [3]. Incidence of TSCI in Ireland was 13.1 per million, comparable to Western Europe where the median incidence is 16 per million per year. This contribution to global mapping is termed high quality yellow data, collected from a prospective study [1]. Only green zone data from countries which have a national registry exceeds this, in terms of quality. We have recently done a retrospective study of

Éimear Smith

eimear.smith@nrh.ie

1 National Rehabilitation Hospital, Rochestown Avenue, Dun Laoghaire, Co. Dublin, Ireland

2 Mater Misericordiae University Hospital, Dublin 7, Ireland

3 School of Public Health, Physiotherapy and Sports Science, University College Dublin, Dublin, Ireland

4 Spine/Trauma Clinical Fellowship, University of Toronto, Sunnybrook Health Sciences Centre, Toronto, Canada
TSCI epidemiology in Ireland, from 2010-2015 to assist with health services planning nationally [4]. This revealed that the incidence of TSCI ranged from 11.5 to 13.3 per million per year over that study period [4]. Falls were the most common cause of injury and incomplete tetraplegia, the most common sub-group of injury [4]. Mean age at injury onset was lowest in 2010, 44.1 (19.3) years and highest in 2014, 52.6 (20.1) years [4].

However, prospective data collection is recommended to achieve the highest quality information [5]. Countries which have published recent prospective epidemiological updates include Italy, the Czech Republic, South Africa and Botswana [6-9] while in the United States, epidemiological data is constantly updated through the Spinal Cord Injury National Statistical Center [10].

As the only previous prospective study in Ireland is now 18 years old, it was our objective to update this information and where possible, improve the quality of data from that study. Our target was to capture all cases of TSCI in Ireland during 2016 and not just those admitted to the National Rehabilitation Hospital. We have previously demonstrated that collection of complete population-based data is possible, probably easier in countries of smaller size [11]. We also sought to ensure optimal accuracy of the population 
denominator by carrying out this study in the same year as a national census.

\section{Methods}

All cases of newly acquired TSCI in Ireland during 2016 were included in this study. Cases were identified at the time of referral or admission to hospital - this was either the National Spinal Injuries Unit in the Mater Hospital or one of the 2 neurosciences centres in the country, Beaumont Hospital Dublin and Cork University Hospital. Patients' consent to have their data included in the study was obtained. The ISCoS core data set was completed on all cases to give information on gender, age at onset, SCI level and ASIA impairment scale, aetiology, details of vertebral and associated injuries, need for surgery, length of stay, discharge destination and long-term ventilator requirements [12]. Descriptive statistics are presented. For continuous variables, mean and standard deviations (SD) or medians and interquartile ranges (IQR) are reported. For categorical variables, crude data, frequencies and percentages are reported. ISCoS reporting guidelines are used where appropriate [13]. Population denominator was the 2016 national census result [14].

\section{Results}

During 2016, there were 61 newly acquired cases of TSCI in Ireland, 12.8 per million. Five of these did not survive the first year post-injury; only 1 of these 5 survived through the acute hospital and rehabilitation phases of care while the other 4 did not survive beyond the acute hospital. Table 1 displays a summary of the results. Of the 6 "other" injury aetiologies, 3 were iatrogenic and 3 were occupational. There were no cases of assault. Incomplete tetraplegia was the commonest neurological presentation, accounting for 28 (45.9\%) injuries, followed by complete tetraplegia, 13 (21.3\%); incomplete paraplegia, $12(19.7 \%)$ and complete paraplegia, $8(13.1 \%)$.

Spinal column injury occurred in $44(72.1 \%)$ and associated injury in $14(23 \%)$; surgical intervention was carried out in $47(77 \%)$. Two $(3.3 \%)$ required ventilatory assistance. In Table 2 , the number $(\%)$ of cases per age category is reported and Table 3 contains the incidence per age category for both genders.

\section{Discussion}

This study is a population-based update on the only previous prospective study of TSCI epidemiology carried out
Table 1 Clinical \& demographic details of traumatic spinal cord injury in Ireland, 2016

\begin{tabular}{ll}
\hline Total number of cases & 61 \\
Overall crude incidence (per million) & 12.8 \\
Survivor crude incidence (per million) & 11.8 \\
Males, $n$ (\%) & $46(75.4)$ \\
Age (years) mean, SD & $52.8,19.9$ \\
Level/AIS, $n$ (\%) & \\
C1 - C4 AIS A, B, C & $16(26.2)$ \\
C5 - C8 AIS A, B, C & $8(13.1)$ \\
T1 - S5 AIS A, B, C & $16(26.2)$ \\
AIS D & $20(32.8)$ \\
AIS E & $1(1.6)$ \\
Aetiology, $n$ (\%) & $37(60.7)$ \\
Fall & $6(9.8)$ \\
Transport & $12(19.7)$ \\
Sports/leisure activities & $6(9.8)$ \\
Other & $94,65-128$ \\
Rehabilitation length of stay - days (median, IQR) & \\
Discharge destination, $n(\%)$ & $36(59)$ \\
Home & $10(16.4)$ \\
Other hospital & $10(16.4)$ \\
Nursing home & $1(1.6)$ \\
Other & $4(6.6)^{\mathrm{a}}$ \\
Deceased & \\
\hline ane other patient was deceased by 1 year post-injury but he had \\
participated in rehabilitation and was discharged to a nursing home, \\
before dying.
\end{tabular}

Table 2 Number (\%) of cases of TSCI per age category

\begin{tabular}{lr}
\hline Age group & $n(\%)$ \\
\hline $16-30$ years & $10(16.4)$ \\
$31-45$ years & $12(19.7)$ \\
$46-60$ years & $15(24.6)$ \\
$61-75$ years & $16(26.2)$ \\
$\geq 76$ years & $8(13.1)$ \\
\hline
\end{tabular}

Table 3 Age and gender specific TSCI incidence (per million)

\begin{tabular}{lll}
\hline Age group & Male incidence & Female incidence \\
\hline 16-30 years & 18.2 & 2.3 \\
31-45 years & 20.2 & 3.5 \\
46-60 years & 32.2 & 4.5 \\
61-75 years & 31 & 20.2 \\
$\geq 76$ years & 39.9 & 28.9 \\
\hline
\end{tabular}

in Ireland in 2000. Two aspects of this study may contribute to improvements compared with the last prospective study of TSCI in Ireland - all cases of TSCI are included and not just those who entered rehabilitation; population 
denominator is based on census figures from the same year as data collection. It shows that the crude incidence of TSCI has changed very little since then. In 2000, there were 13.1 cases per million population surviving to rehabilitation. In 2016, there were 12.8 cases per million in total. This incidence is marginally lower than some of the most recently reported Western European figures, ranging from 14.7 to 21.7 per million per year $[6,7,15,16]$.

Compared with 2000, there appears to have been a change in the aetiologies of injuries. Falls, now accounting for $60.7 \%$ of causes of TSCI have replaced road collisions, which were $50 \%$ of TSCI in 2000, as the leading aetiology [3]. Other European nations report similar aetiological trends with falls accounting for $40.9-54.2 \%$ of the causes of TSCI $[6,7,15,16]$. It is notable that road collisions were not even the 2nd leading cause of TSCI in Ireland in 2016, having been replaced by sports/leisure activities, similar to a recent finding in Switzerland [15]. Although difficult to prove causality, improved road safety measures have probably had a role to play in this in Ireland, as in other countries $[17,18]$. It may be noted by readers that there is no reference to assault in aetiologies. This is because assault is a very uncommon cause of TSCI in Ireland, sometimes not occurring at all during a calendar year, in stark contrast to other jurisdictions [8]. Finally, the 3 cases of iatrogenic injury included under the term "other" and accounting for $4.9 \%$ of injuries is constant in Ireland [4] but less common than that reported elsewhere [19].

Median, rather than mean age at injury was reported in the 2000 study; this was 37 years [3]. We reported mean age here but we know the median age in 2016 was 55 years, considerably higher than in 2000 [3]. Increasing age at TSCI onset is well documented in developed countries $[6,7$, $10,15,16]$ and there appears to be a trend of more older people sustaining falls resulting in incomplete tetraplegia. This picture was also evident in our retrospective study [4].

Not all studies use the ISCoS reporting guidelines for classification by injury level/ASIA impairment scale so direct comparison is not always possible. It is more common for TSCI to be reported as complete or incomplete tetraplegia or paraplegia. Using this method, incomplete tetraplegia was the most common neurological presentation $(28,45.9 \%)$, similar to the most recent figures from the United States [10].

Our age and gender specific incidence rates show slightly different trends to those elsewhere [7, 15]. In Ireland, there is a sustained upward trajectory in incidence rates with increasing age while in Italy and Switzerland, it is the younger and older age groups which display the highest incidences, akin to what was historically termed the bimodal peak $[7,15]$.

Few other epidemiological studies reported data on length of stay or discharge destination. We reported median length of stay, due to the fact that a very small numbers of cases had prolonged rehabilitation stays; this was 94 days. In Finland, median length of stay was 104 days for those under 60 years old but only 40.5 days for those over 60 [20]. Our home discharge rate of $59 \%$ is slightly better than that in Finland $(53.2 \%)$ but worse than that in Spain $(88.8 \%)[16,20]$.

The main strength of this study that it is population based, a feature that is not always so easy, in medium-sized or larger countries $[7,16]$. Limitations of this study are that patients, who were deceased prior to hospitalisation, could not be included. Secondly, in-depth statistical analysis was not possible due to the small numbers of patients.

\section{Conclusion}

This study provides updated prospective epidemiological information for the next global mapping of TSCI. Overall incidence has changed very little but there has been a change in demographics, aetiologies and patterns of injury. A similar study on NTSCI nears completion and will contribute to the next NTSCI update.

Acknowledgements Maeve McEnery, Research Assistant

\section{Compliance with ethical standards}

Conflict of interest The authors declare that they have no conflict of interest.

Publisher's note: Springer Nature remains neutral with regard to jurisdictional claims in published maps and institutional affiliations.

\section{References}

1. Lee BB, Cripps RA, Fitzharris M, Wing PC. The global map for traumatic spinal cord injury epidemiology: update 2011, global incidence rate. Spinal Cord. 2014;52:110-11.

2. New PW, Cripps RA, Lee BB. Global maps of non-traumatic spinal cord injury epidemiology: towards a living data repository. Spinal Cord. 2014;52:97-109.

3. O'Connor RJ, Murray PC. Review of spinal cord injuries in Ireland. Spinal Cord. 2006;44:445-8.

4. Smith É, Fitzpatrick P, Murtagh J, Lyons F, Morris S, Synnott K. Epidemiology of traumatic spinal cord injury in Ireland, 2010 2015. Neuroepidemiology. 2018;51:19-24.

5. Cripps RA, Lee BB, Wing P, Weerts E, Mackay J, Brown D. A global map for traumatic spinal cord injury epidemiology: towards a living data repository for injury prevention. Spinal Cord. 2011;49:493-501.

6. Kriz J, Kulakovska M, Davidova H, Silova M, Kobesova A. Incidence of acute spinal cord injury in the Czech Republic: a prospective epidemiological study 2006-2015. Spinal Cord. 2017;55:870-4.

7. Ferro S, Cecconi L, Bonavita J, Pagliacci MC, Biggeri A, Franceschini M for the Italian Study Group. Incidence of traumatic 
spinal cord injury in Italy during 2013-2014: a population based study. Spinal Cord. 2017;55:1103-7.

8. Joseph C, Delcarme A, Vlok I, Wamhan K, Phillips J, Nilsson Wikmar L. Incidence and aetiology of traumatic spinal cord injury in Cape Town, South Africa: a prospective, population-based study. Spinal Cord. 2015;53:692-6.

9. Lofvenmark I, Norrbrink C, Nilsson-Wikmar L, Hultling C, Chakandinakira S, Hasselberg M. Traumatic spinal cord injury in Botswana: characteristics, aetiology and mortality. Spinal Cord. 2015;53:150-4

10. National Spinal Cord Injury Statistical Center. Facts and Figures at a Glance. Birmingham, Alabama: University of Alabama at Birmingham; 2017.

11. Smith É, Fitzpatrick P. Epidemiology of spinal cord injury in Ireland. Part 1: Evaluation of record accuracy and results of a feasibility study. Conference proceedings. Montreal: ISCoS/ASIA scientific meeting; 2015.

12. DeVivo M, Biering-Sorensen F, Charlifue S, Noonan V, Post M, Stripling T, et al. Executive committee for the international SCI data sets committees. international spinal cord injury core data sets. Spinal Cord. 2006;44:535-54.

13. DeVivo MJ, Biering-Sorensen F, New P, Chen Y. Standardization of data analysis and reporting of results from the International Spinal Cord Injury Core Data Set. Spinal Cord. 2011;49:596-9.
14. Central Statistics Office. Census 2016 report. Available at: http://www.cso.ie/en/census/census2016reports/.

15. Chamberlain JD, Deriaz O, Hund-Georgiadis M, Meier S, ScheelSailer A, Schubert M, et al. Epidemiology and contemporary risk profile of traumatic spinal cord injury in Switzerland. Inj Epidemiol. 2015;2:28.

16. Montono-Marqués A, Ferreiro-Velasco ME, Salvador-de la Barrera S, Balboa-Barreiro V, Rodriguez-Sotillo A, MeijideFailde R. Epidemiology of traumatic spinal cord injury in Galicia, Spain: trends over a 20 -year period. Spinal Cord. 2017;55:588-94.

17. Smith É, Brosnan M, Comiskey C, Synnott K. Road collisions as a cause of traumatic spinal cord injury in Ireland, 2001-2010. Top Spinal Cord Inj Rehabil. 2014;20:158-65.

18. O'Connor PJ. Prevalence of spinal cord injury in Australia. Spinal Cord. 2005;43:42-46.

19. Montalva-Iborra A, Alcanyis-Alberola M, Grao-Castellote C, Torralba-Collados F, Giner-Pascual M. Risk factors in iatrogenic spinal cord injury. Spinal Cord. 2017;55:818-22.

20. Koskinen EA, Alen M, Väärälä EM, Rellman J, Kallinan M, Vainionpää A. Centralised spinal cord injury care in Finland: unveiling the hidden incidence of traumatic injuries. Spinal Cord. 2014;52:779-84. 